\title{
Foreign body aspiration
}

\author{
Divyansh Bajaj ${ }^{1}$, Ashutosh Sachdeva ${ }^{2}$, Desh Deepak ${ }^{3}$ \\ ${ }^{1}$ Department of Medicine, Quinnipiac University Frank H. Netter MD School of Medicine, St. Vincent's Medical Center, Bridgeport, CT, USA; \\ ${ }^{2}$ Division of Pulmonary and Critical Care, Department of Medicine, University of Maryland School of Medicine, Baltimore, MD, USA; ${ }^{3}$ Department \\ of Respiratory Medicine, Dr. RML Hospital \& Atal Bihari Vajpayee Institute of Medical Sciences, New Delhi, India \\ Contributions: (I) Conception and design: D Bajaj, D Deepak; (II) Administrative support: A Sachdeva; (III) Provision of study materials or patients: D \\ Deepak, A Sachdeva; (IV) Collection and assembly of data: None; (V) Data analysis and interpretation: None; (VI) Manuscript writing: All authors; \\ (VII) Final approval of manuscript: All authors. \\ Correspondence to: Desh Deepak, MBBS, MD. Department of Respiratory Medicine, Dr. RML Hospital \& Atal Bihari Vajpayee Institute of Medical \\ Sciences, New Delhi 110001, India. Email: drdeepak.rml@gmail.com.
}

\begin{abstract}
The clinical manifestations of foreign body $(\mathrm{FB})$ aspiration can range from an asymptomatic presentation to a life-threatening emergency. Patients may present with acute onset cough, chest pain, breathlessness or sub-acutely with unexplained hemoptysis, non-resolving pneumonia and at times, as an incidental finding on imaging. Patients with iatrogenic FB such as an aspirated broken tooth during difficult intubation or a broken instrument are more common scenarios in the intensive care unit (ICU). Patients with post-obstructive pneumonia with or without sepsis, or variable degree of hemoptysis often require ICU level of care and bronchoscopic interventions. Rigid bronchoscopy has traditionally been the modality of choice; however, with the innovation in instrumentation and wider availability of flexible bronchoscopes, most of the FB removal is now successfully performed using flexible bronchoscopy. Proceduralists choose instruments in accordance with their training and expertise. We describe the use of most common instruments including forceps, balloon catheters, and baskets. Role of cryoprobe and LASER in FB removal is reviewed as well. In general, larger working channel bronchoscopes are preferred; however, smaller working channel bronchoscopes may be used in situations when the patients are intubated with a smaller diameter endotracheal or tracheostomy tubes. Large size FB are removed en bloc with the grasping tool, bronchoscope, and endotracheal or tracheostomy tube, requiring preparation to safely re-establish the airway. After FB removal, bronchoscopy is re-performed to identify any residual FB, assess any injury to the airway, suction post-obstructive secretions or pus, control any active bleeding and remove granulation tissue that may be obstructing the airway. Additional interventions like balloon dilatation may be required to dislodge an impacted FB or to maintain patency of bronchial lumen. If bronchoscopic methods fail, surgery may be required for retrieval of FB in symptomatic patients or to resect suppurative or necrotizing lung process. Multidisciplinary approach involving intensivists, surgeons, and anesthesiologists is the key to optimal patient outcomes.
\end{abstract}

Keywords: Foreign body (FB) aspiration; bronchoscopy; intensive care

Submitted Jan 30, 2020. Accepted for publication Mar 13, 2020.

doi: $10.21037 /$ jtd.2020.03.94

View this article at: http://dx.doi.org/10.21037/jtd.2020.03.94

\section{Introduction}

Foreign body (FB) aspiration is an uncommon but potentially life-threatening situation that requires urgent intervention. It occurs more commonly among children than in adults (1). The clinical presentation varies depending on the location of FB in the airway. Patients may be asymptomatic, but when present, symptoms range from acute onset of cough, shortness of breath and at times, asphyxiation. Patients may present sub-acutely with hemoptysis or with post obstructive pneumonia and 
lung abscess formation. Patients who present with acute respiratory failure and require intensive care unit (ICU) admission may have large volume hemoptysis, sepsis from post-obstructive pneumonia, or gas exchange abnormalities due to combination of significant airway obstruction and pre-existing co-morbidities. As such, these patients require timely interventions to remove the FB in order to relieve the obstruction to achieve source control.

A German laryngologist, Gustav Killian, is credited to be the first one to have removed a pork bone from a patient's trachea using a rigid esophagoscope in 1897 (2). This opened the era of rigid bronchoscopy which became a widely used method of FB removal worldwide. Advancement in technology and introduction of flexible bronchoscopy has made it easier to achieve similar results as rigid bronchoscopy in most situations and as such, it is now the preferred approach for FB extraction (3-5). Even so, rigid bronchoscopy holds its utility in select situations, especially in children (4).

In this comprehensive review, we discuss the role of bronchoscopic tools and intervention techniques for $\mathrm{FB}$ removal in the ICU.

\section{Clinical presentation}

The clinical presentation of FB aspiration varies among children and adults. Due to relatively small diameter of the tracheobronchial tree, FB gets lodged in the proximal airways in children resulting in stridor and acute respiratory distress. However, adults usually present with symptoms resulting from distal impaction of the $\mathrm{FB}$. It is more common for a $\mathrm{FB}$ to get impacted in the right bronchial tree due to the straighter alignment of the right mainstem with trachea compared to left. Among adults, most studies show high incidence of FB aspiration in the 45-60 year age group (5-7). Often, adult patients have predisposing risk factors for aspiration, which may include altered mental status, alcohol or drug intoxication, neuromuscular weakness. In certain cases, FB aspiration can also be iatrogenic.

The most common presenting symptom of $\mathrm{FB}$ aspiration is cough, which is a primitive airway protective reflex, and is observed in $58-96 \%$ of the cases (8-11). Other symptoms include wheezing, dyspnea, chest pain, hemoptysis, and recurrent post-obstructive pneumonia $(3,12)$. Multiple case series have reported that patients often do not recall the aspiration event and, therefore, do not report it $(5,7,8,10,13)$. This may result in a delayed diagnosis, sometimes for months and up to many years leading to complications like obstructive emphysema due to ball-valve mechanism, bronchial stenosis, post-obstructive bronchiectasis, necrotizing pneumonia, bronchopleural and bronchocutaneous fistulas, empyema, and osteomyelitis of the rib (14-19). Therefore, symptoms of non-resolving cough or recurrent bronchitis or pneumonia warrant careful clinical evaluation and FB aspiration must be considered even in patients without risk factors.

Patients with FB aspiration admitted to the ICU often, are the ones who develop life threatening airway obstruction, hemoptysis or respiratory failure. Postobstructive necrotizing pneumonia secondary to $\mathrm{FB}$ aspiration may cause hypoxic respiratory failure and some patients may require ventilator support (Figure 1). Rarely, patients may present post-cardiopulmonary arrest after a "choking" episode due to FB aspiration $(20,21)$. In intubated patients, endotracheal tube (ETT) obstruction due to aspirated FB may result in worsening hypoxia and difficulty with oxygenation and ventilation $(22,23)$. The obstruction may be secondary to an aspirated FB or iatrogenic as a result of traumatic intubation, for example, a broken tooth. It is critical to promptly recognize ETT obstruction. Activation of high-pressure alarm on the ventilator, reduced tidal volume delivered, reduced expired end-tidal $\mathrm{CO}_{2}$, severe hypoxemia and inability to pass the suction catheter down the ETT; all may provide clues to the intensivist (23). Diagnostic bronchoscopy is valuable in these circumstances to both diagnose the cause of obstruction and if due to $\mathrm{FB}$, mechanically dislodge the $\mathrm{FB}$ outside the ETT into the tracheobronchial tree. The FB is then removed using the tools and techniques discussed in latter sections. Alternatively, consideration may be given to exchange of ETT especially if the FB is firmly lodged in the lumen of ETT.

\section{Types of aspirated foreign bodies}

It is important to understand the nature and type of $\mathrm{FB}$ aspirated as each FB has distinct characteristics and poses a unique challenge for the bronchoscopist. Also, it helps the proceduralist plan ahead with the choice of tools that may be required for its safe and successful retrieval.

Foreign bodies are broadly classified into: Organic and Inorganic (3). Organic FBs include chicken or fish bones, meat, fruit or vegetable pieces, seeds and tend to be the predominant group (47\%) as reported in a literature review by Blanco Ramos et al. (5). Inorganic FBs include thumbtacks, pins, screws, coins, plastic pieces 

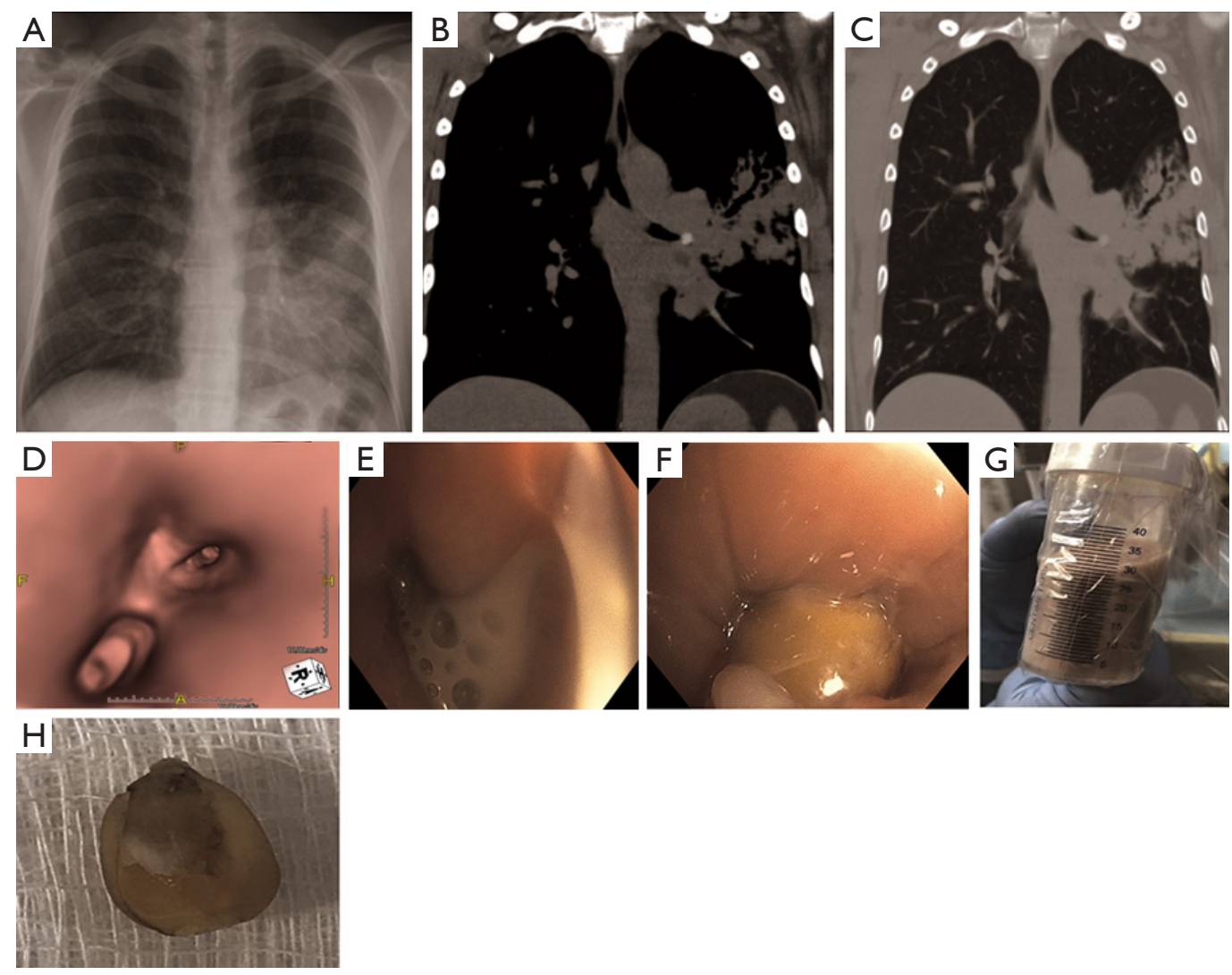

Figure 1 A 46-year old man, never smoker, with history of Asthma presented with non-resolving cough and hemoptysis. He received two prior antibiotic treatments for presumed pneumonia a month apart with mild improvement. Chest imaging revealed findings concerning for necrotizing pneumonia as result of lingular obstruction (A-C). Computed tomography scans revealed high density foreign body (B) and post obstructive bronchiectasis (C). 3-dimensional reconstruction of the tracheobronchial tree was performed to localize the obstruction (D). After receiving intravenous antibiotics for 72 hours, patient was intubated electively given concern for "spill-over" of pus from relief of obstruction. A significant amount of pus was suctioned post-extraction of the foreign body (E-G). Foreign body was determined to be a corn kernel $(\mathrm{H})$. Patient completed a course of antibiotics and had no symptoms on a follow up visit.

etc. Organic FBs are known to cause more complications due to their ability to absorb moisture that often result in airway obstruction and post-obstructive pneumonia. Also, they elicit a strong inflammatory reaction within the bronchial tissue, thus, making their extraction much more challenging (13). The ability to hold moisture does help when using cryoprobe for extraction of organic FB and it is tool of choice for many proceduralists (Figure 2). Inorganic FBs do not possess absorbent properties, hence difficult to retrieve using cryoadhesion and require grasping tools.

Patients generally present with accidental aspiration of FB. However, aspiration may be iatrogenic which poses a different set of challenges. Iatrogenic FBs such as tooth (Figure $3 A$ ), dental prostheses, endoscopic capsules, broken instrument pieces (Figure 3B), etc., may get lodged in the airway inadvertently during invasive procedures like endotracheal intubation $(24,25)$, laryngoscopy or rigid bronchoscopy (26), and administration of anesthesia (27). Timely recognition and retrieval are important to prevent any post-obstructive complications such as necrotizing pneumonia, lung abscess, hemoptysis, empyema, and resultant sepsis or respiratory failure.

\section{Diagnostic evaluation}

Bronchoscopy is the mainstay in diagnosis and management of FB aspiration. While it may be the only diagnostic modality in emergent situations, when patient is stable, other diagnostic testing may be performed during preprocedural planning to reduce the complications and 

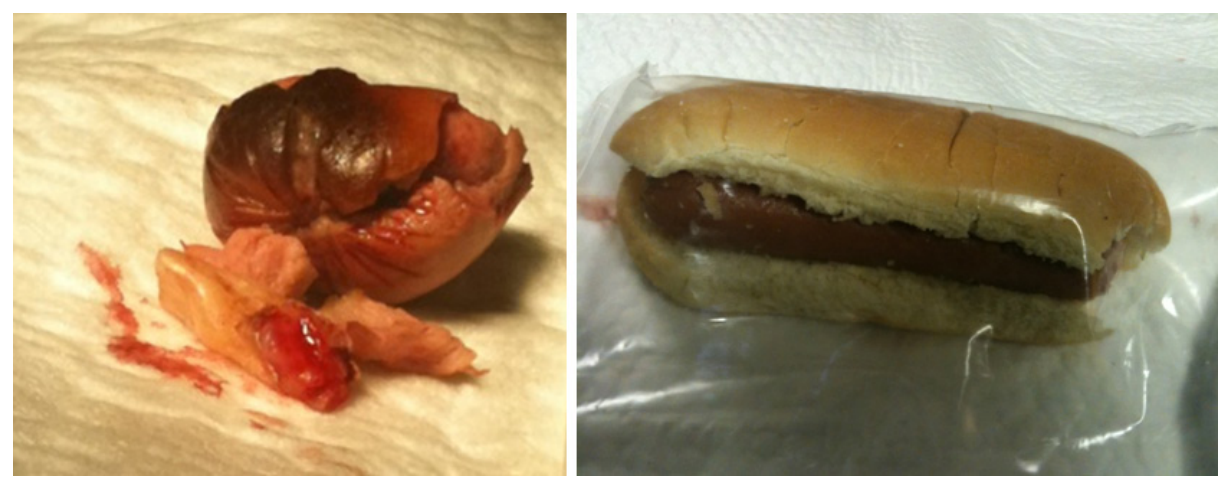

Figure 2 An 80-year-old gentleman presented with acute respiratory failure requiring intubation and mechanical ventilation, a few hours after a witnessed choking episode with the first bite of a "hot-dog". Cryotherapy extraction of the foreign body was performed and the patient was extubated the following morning. He received a short course of antibiotics to manage post-obstructive pneumonia.
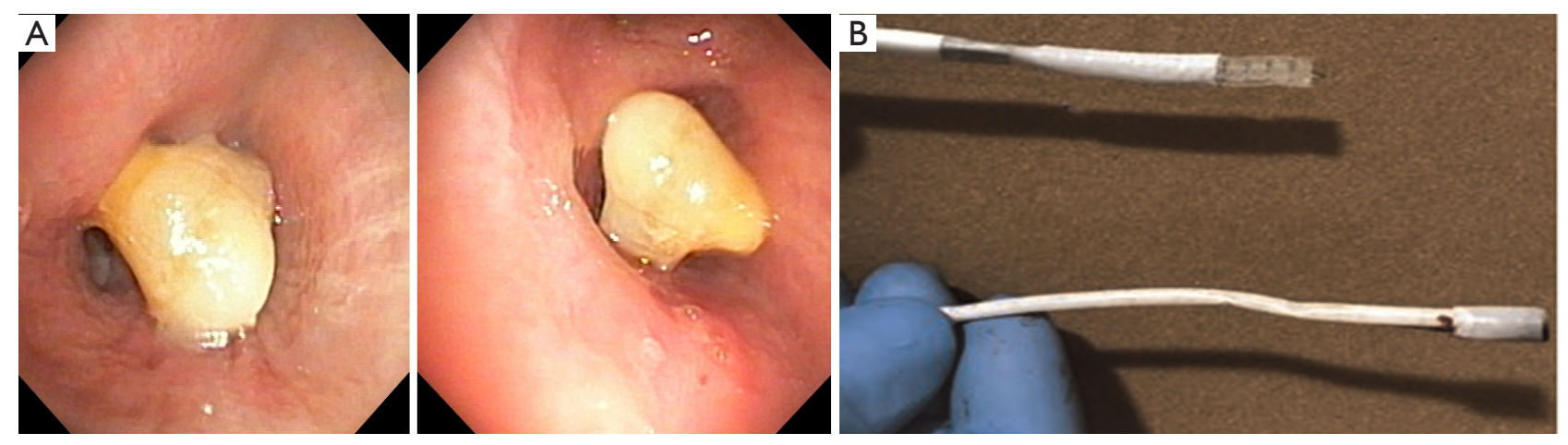

Figure 3 Examples of iatrogenic foreign body aspiration. (A) A 78-year-old gentleman was emergently intubated for acute respiratory failure and a tooth was dislodged into the bronchus intermedius. Bronchoscopy was performed for hemoptysis a few days after the intubation and the diagnosis of iatrogenic foreign body impaction was made. (B) Image of a broken disposable bronchoscope $\left(\right.$ AMBU $\left.{ }^{\circledR}\right)$ that was inadvertently introduced via "Murphy eye" of a size 8.0 endotracheal tube. This resulted in iatrogenic foreign body that required removal using a forceps. One jaw of the forceps was engaged in the lumen of the broken scope and grasped to extract in its entirety.

enhance the outcomes.

The initial diagnostic evaluation of patients with suspected FB aspiration includes obtaining a posteroanterior and lateral chest radiograph. The visibility of the aspirated FB depends on its radio-opacity, size, anatomical position in the airway and the patient's body habitus. Organic foreign bodies like food particles and wood are generally radiolucent while inorganic ones like coins, stone particles, metals, glass pieces etc. are radiopaque. It is estimated that only around $26 \%$ of the aspirated FBs are radio-opaque and visible on chest radiographs (5). Indirect signs of FB aspiration seen on chest radiography include hyper-lucency suggesting air trapping (Figure 4), atelectasis, consolidation, and mediastinal shift. Blanco Ramos et al. reported the incidence of these radiological findings from various case series as: Consolidation (43\%), atelectasis (15\%) and bronchiectasis (5\%) though absence of these does not exclude FB aspiration (5).

Computed tomography (CT) of chest helps in localizing and evaluating the nature of the $\mathrm{FB}$ and provides better information compared to a plain chest radiograph. The $\mathrm{FB}$ is visible on CT in $62 \%$ cases and helps in identifying concomitant or indicative consolidation, atelectasis, pleural effusion and bronchial wall abnormalities (28). Intra-operative ultrasonography is occasionally employed to identify sub-pleural radiolucent foreign bodies. Fluoroscopy provides real time images and is rarely used for FB evaluation (29). It has been used intraprocedurally to guide forceps especially, when the FB gets lodged distally (30-32). 

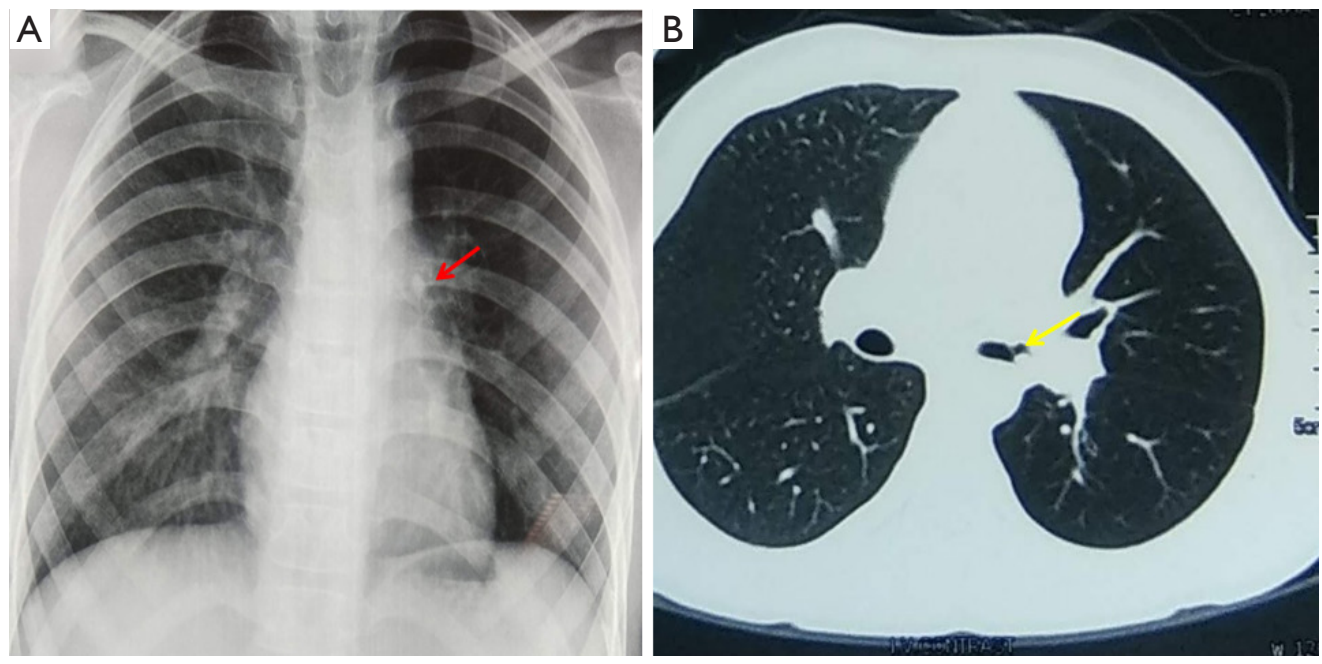

Figure 4 A 13-year-old boy presented with history of whistling sound while breathing. A history of aspirating components of a plastic whistle 6 weeks back was elicited. (A) Chest X-ray demonstrates hyper-lucency of left lung with opacity (red arrow) in left hilar region. (B) Computed tomography showed a reverse C shaped artifact (yellow arrow) in left main bronchus with hyperinflation of left lung fields. A plastic whistle component was removed using sharktooth forceps that revealed significant granulation of the surrounding mucosa that was managed conservatively. Repeat bronchoscopy after 2 months showed normal lumen with mild inflammatory changes.

\section{Bronchoscopy in evaluation and management of FB aspiration}

Rigid bronchoscopy was introduced in 1897 for FB removal and was widely used until the advent of flexible bronchoscopy by Shigeto Ikeda in 1968. This has transformed the field of bronchoscopy including the management of $\mathrm{FB}$ removal (33). Flexible bronchoscopy allows better visualization of distal airways and can be performed under local anesthesia and moderate sedation though general anesthesia may be more conducive to removal of impacted FB. Overtime, with advancement in bronchoscopic tools and experience with flexible bronchoscopy, it has become the standard technique for initial evaluation and management of FB aspiration among adults $(5,8,13,34)$.

The success rate of flexible bronchoscopy in retrieval of airway FBs has been studied in numerous case series. Sehgal et al. performed a large single center retrospective study including data from 25,998 flexible bronchoscopies, of which 65 were done for FB removal (13). The authors report that a FB was encountered in 49 cases, of which 45 were successfully removed with flexible bronchoscopy, an overall success rate of $92 \%$. The authors also performed a systematic review and reported a success rate ranging between from $61 \%$ to $100 \%$, with a pooled success rate of $89.6 \%(13)$.

While flexible bronchoscopy is the most common modality for FB removal among adults today, rigid bronchoscopy retains its utility. It is the mainstay for FB removal in children and adolescents (35). $\mathrm{Ng}$ et al. compared flexible and rigid bronchoscopy including factors to consider while choosing one modality versus the other in adult FB aspiration. They found that rigid bronchoscopy was preferred in patients with no comorbidities, previous failed attempt to remove $\mathrm{FB}$, a longer duration of aspiration and FB of hard consistency (28) (Figure 5). In the latter situation, rigid bronchoscopy is particularly preferred as rigid instruments allow better transfer and control of force in extracting hard and impacted foreign bodies. Also, it allows access to larger suction as significant bleeding may occur with manipulation during extraction of impacted FB, particularly the ones lodged in airway for longer duration.

\section{Preprocedural planning}

FB removal can be challenging and requires proper planning and organization. Careful history taking and imaging review helps with understanding the nature of FB and thus the tool selection. It is essential for the bronchoscopist to study the size, shape and the position of the FB before any intervention. Organizing the required bronchoscopic instruments and review of procedure plan with the staff is extremely helpful at the time of the procedure. Appropriate 

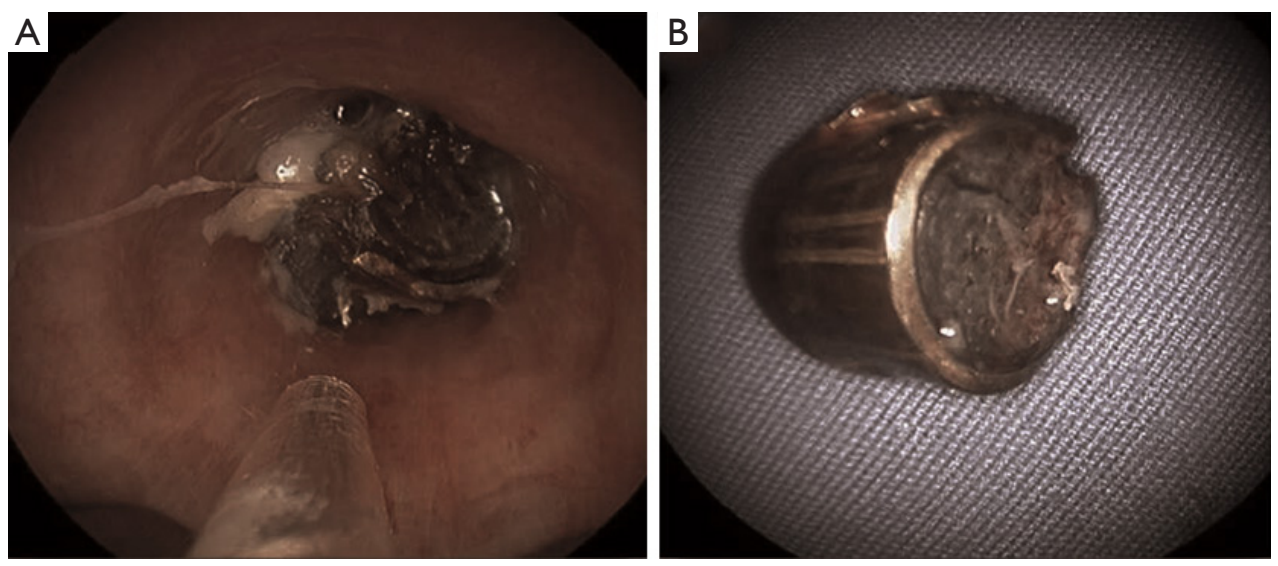

Figure 5 Impacted foreign body in the right lower lobe in a patient presenting with mandibular fractures as a result of firearm injury. (A) Foreign body accessed via a 12-mm Bryan-Dumon rigid bronchoscope; (B) A 9-mm bullet shell was extracted from bronchus intermedius using rigid forceps. Interestingly, there were no other associated injuries in the bullet path likely due to loss of velocity at the site of its impact in the mandibular bone.

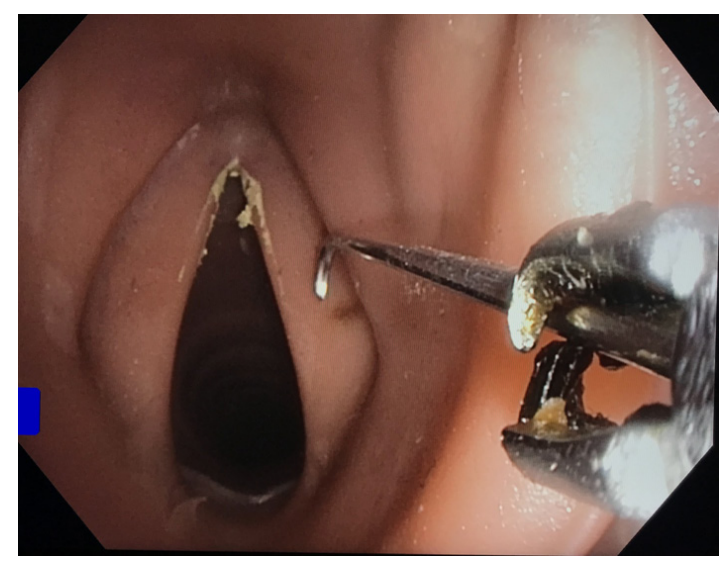

Figure 6 Rat tooth forceps being used for the retrieval of airway foreign body in a simulation session.

patient positioning, such as Trendelenburg position, is helpful in preventing the distal movement of the FB and making it easy for retrieval (36). Authors prefer to have a rigid bronchoscope available, even when flexible bronchoscopy is chosen as the primary modality.

\section{Bronchoscopic tools and techniques}

Bronchoscopy for $\mathrm{FB}$ removal requires proper instruments for its safe retrieval. The choice of instrument depends on the type of $\mathrm{FB}$, inorganic versus organic, and at times on the shape, size, and contour. We discuss some of the most useful instruments in this section.

\section{Forceps}

Forceps have been used with bronchoscopic procedures for a long time. It is one of most common instruments used for $\mathrm{FB}$ extraction $(7,37,38)$. Different types of forceps are available to use in the removal of a variety of foreign bodies. Forceps vary from each other depending on the presence or absence of teeth, the shape of the teeth (if present), fenestrations and centrally placed needle assembly. Toothed forceps are used to hold non friable objects like coins, bones and plastics. The most commonly used toothed forceps are rat tooth (Figure 6), shark tooth and alligator forceps. Sharp or smooth objects are often grasped with forceps with rubber tips to prevent injury to the surrounding airway tissue during retrieval. Forceps are usually not used to retrieve friable objects like food, nuts as grasping them with forceps leads to their break down.

Imaging review is quite helpful in assessing the size of FB. This information is then applied to select a forcep with an opening width that is likely to be sufficient to grasp the object. A bronchoscope with a compatible working channel is then used to perform the procedure. The 'jaws' of the forceps need to align with the $\mathrm{FB}$ in a way that maximal opening diameter is perpendicular to the FB. A careful nudging of the FB with a closed forceps or rotation of the catheter proximally with distal translation may be required to align it for an optimal relationship. The jaws should be kept in proximity to the distal tip of bronchoscope to have a view and maximal control of the instrument. The forceps with its jaws open are then advanced to grasp the 
Table 1 Types and features of commonly used forceps used for bronchoscopic foreign body retrieval

\begin{tabular}{|c|c|c|c|c|c|c|c|}
\hline $\begin{array}{l}\text { Instrument } \\
\text { name }\end{array}$ & Manufacturer & $\begin{array}{l}\text { Single use/ } \\
\text { Resuable }\end{array}$ & $\begin{array}{l}\text { Minimum channel } \\
\text { size }(\mathrm{mm})\end{array}$ & $\begin{array}{l}\text { Working length } \\
(\mathrm{cm})\end{array}$ & $\begin{array}{l}\text { Opening width } \\
\qquad(\mathrm{mm})\end{array}$ & Features & Image \\
\hline $\begin{array}{l}\text { V-shape } \\
\text { grasping } \\
\text { forceps }\end{array}$ & Olympus ${ }^{\mathrm{TM}}$ & Reusable & $2.6 ; 2.0$ & $105 ; 165$ & $13 ; 13$ & $\begin{array}{l}\text { Assists in retrieval of thin, } \\
\text { flat objects, such as fish } \\
\text { bones, coins, dentures, } \\
\text { jewelry }\end{array}$ & Figure 7 (39) \\
\hline $\begin{array}{l}\text { Shark tooth } \\
\text { grasping } \\
\text { forceps }\end{array}$ & Olympus ${ }^{\mathrm{TM}}$ & Reusable & 2.8 & 105 & 4.7 & $\begin{array}{l}\text { Large jaw and sharp } \\
\text { tooth; similar to rat tooth } \\
\text { forceps in use }\end{array}$ & Figure 9 (41) \\
\hline $\begin{array}{l}\text { Rubber tip } \\
\text { grasping } \\
\text { forceps }\end{array}$ & Olympus ${ }^{\mathrm{TM}}$ & Reusable & 2 & 190 & 4.8 & $\begin{array}{l}\text { Assists in retrieval of } \\
\text { sharp or flat objects, such } \\
\text { as nails, needles, pins, } \\
\text { and blades }\end{array}$ & Figure $10(42)$ \\
\hline $\begin{array}{l}\text { Mini three- } \\
\text { prong grasping } \\
\text { forceps }\end{array}$ & Olympus ${ }^{\mathrm{TM}}$ & Single use & 1.2 & 115 & 10 & $\begin{array}{l}\text { Assists in retrieval of } \\
\text { irregular shaped objects, } \\
\text { such as food }\end{array}$ & Figure $11(43)$ \\
\hline
\end{tabular}

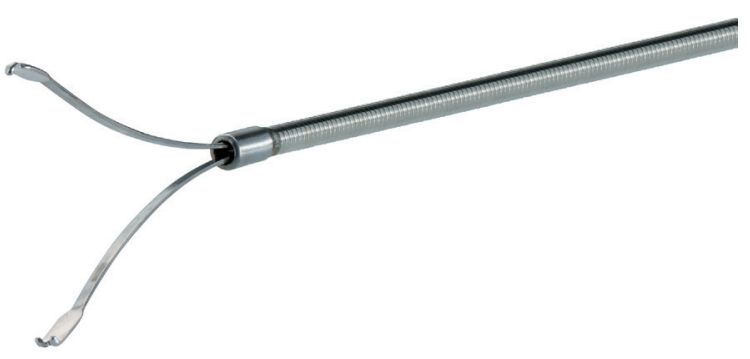

Figure $7 \mathrm{~V}$-shape grasping forceps.

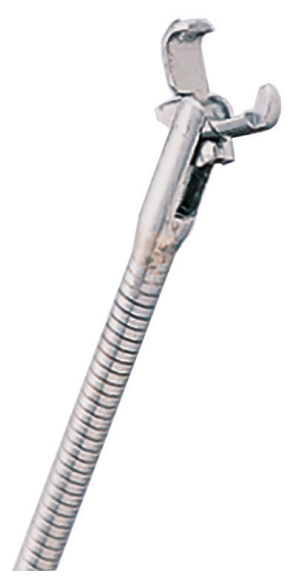

Figure 8 Rat tooth grasping forceps.
Figure 9 Shark tooth grasping forceps.

FB without injuring surrounding tissue. Once the grip is obtained, slight rotational force may be needed to release the FB from the airway wall. The forceps with the FB and the bronchoscope are withdrawn together in a co-axial motion. Table 1 summarizes the types and features of forceps used for FB retrieval. 


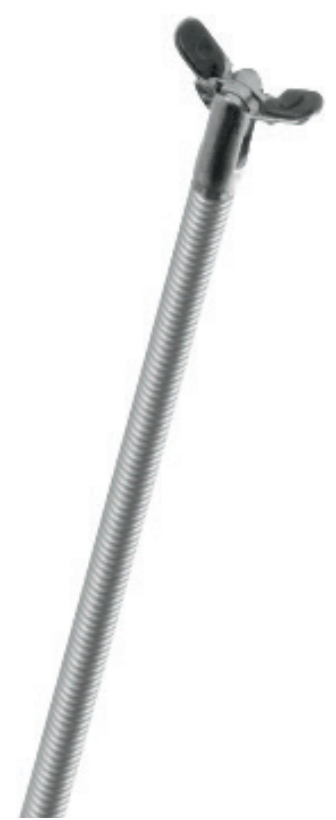

Figure 10 Rubber tip grasping forceps.

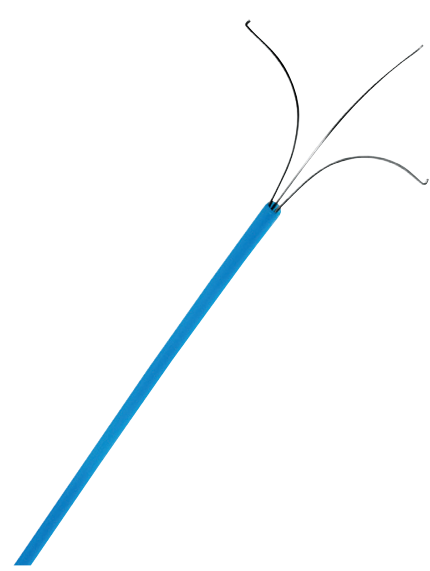

Figure 11 Mini three-prong grasping forceps.

\section{Baskets}

Baskets are commonly used tools with flexible bronchoscopy. They are usually employed to retrieve large objects that have irregular contour and where it is difficult to get the jaws of the forceps across the width of the FB to get a good grasp. Table 2 summarizes the types and features of baskets used for FB retrieval. Common types of baskets and their use are discussed next.

Dormia basket was developed by an Italian Urologist,
Dormia (48) and was first used for removal of ureteral stones. Overtime, its use has been extended to extraction of biliary stones, food bolus impactions, and FB removal in the airway. Various versions that consist of three, four or six wires of different materials to form a basket attached to a single lead point are available.

Zero tip baskets are used in the extraction of FBs from distal bronchi (Figure 16). These baskets have a tip-less design and a flattened distal surface that aids in reducing the contact interface between the instrument and the surrounding tissue. This unique design allows for smooth manipulation of the basket in close vicinity of the FB $(49,50)$.

The basket, retracted into its sheath, is introduced through the working channel. If there is a space between the FB and the luminal wall, the sheath is pushed alongside, taking care not to push the FB distally. As the sheath reaches distally, the basket is deployed. The flared basket is then pulled back with rotational motion to engage the FB. Once the FB is inside the basket, the wires are retracted back (or sheath is advanced over the wired basket) to have a firm grip. Caution should be exercised not to retract too hard as friable objects may break into pieces and fall out of the basket. If the sheath cannot be pushed distally to the object or if there is no distal space to flare open the basket, it may be opened proximally and then pushed distally with rotational motion to gently engage the FB. However, this is often difficult as the wires tend to bend with a forward push. Once a firm grip is obtained, the whole assembly is removed maintaining co-axial motion under vision.

Fishnet basket is particularly, useful for removal of large and friable objects (3). It consists of a mesh of wires which are intertwined to form a basket. The fishnet basket is inserted through the working channel of a bronchoscope. The thin and flexible loops are gently pushed in between the mucosa and the FB to reach past the distal end and then flared so that FB falls in the basket. Once, the FB gets "trapped" by the fishnet, the basket is gently closed by proximal retraction. The FB, basket and the bronchoscope are removed en bloc. Fishnet baskets are difficult to manipulate in a small distal airway as the net requires adequate space when unfolded. This is not the case with the wired baskets which can be easily maneuvered in a small airway.

Snares are rarely used for retrieval of large foreign bodies located in central or distal airways. In contrast to baskets that have multiple wires to loop around the object in different dimensions, snares have a loop of wire that opens in a single dimension. They are considered less traumatic 
Table 2 Types and features of commonly used baskets used for bronchoscopic foreign body retrieval

\begin{tabular}{|c|c|c|c|c|c|c|c|c|}
\hline $\begin{array}{l}\text { Instrument } \\
\text { name }\end{array}$ & Manufacturer & $\begin{array}{l}\text { Single use/ } \\
\text { reusable }\end{array}$ & $\begin{array}{l}\text { Minimum channe } \\
\text { size }(\mathrm{mm})\end{array}$ & $\begin{array}{l}\text { el Working } \\
\text { length }(\mathrm{cm})\end{array}$ & $\begin{array}{l}\text { Distal tip diameter } \\
\quad \text { (French) }\end{array}$ & $\begin{array}{l}r \text { Opening } \\
\text { width }(\mathrm{mm})\end{array}$ & Features & Images \\
\hline $\begin{array}{l}\text { Mini grasping } \\
\text { basket }\end{array}$ & Olympus ${ }^{\mathrm{TM}}$ & Single use & $1.2 / 1.2$ & $115 / 115$ & $3 / 2.4$ & $11 / 9$ & $\begin{array}{l}\text { Assists in retrieval of } \\
\text { smooth, rounded objects, } \\
\text { such as peanuts and } \\
\text { almonds. Small size allows } \\
\text { it to be used through smaller } \\
\text { channel bronchoscopes }\end{array}$ & $\begin{array}{l}\text { Figure } 12 \\
(44)\end{array}$ \\
\hline $\begin{array}{l}\text { Grasping } \\
\text { basket }\end{array}$ & Olympus ${ }^{\mathrm{TM}}$ & Reusable & 2 & 155 & & 32 & $\begin{array}{l}\text { Assists in retrieval of } \\
\text { smooth, rounded objects }\end{array}$ & $\begin{array}{l}\text { Figure } 13 \\
(45)\end{array}$ \\
\hline $\begin{array}{l}\text { Zero tip airway } \\
\text { retrieval } \\
\text { basket }\end{array}$ & $\begin{array}{l}\text { Boston } \\
\text { Scientific }{ }^{\mathrm{TM}}\end{array}$ & Single use & $1 / 1.2$ & $120 / 120$ & & $12 / 16$ & $\begin{array}{l}\text { Aids in accessing the } \\
\text { upper lobes where rigid } \\
\text { bronchoscopy may be } \\
\text { insufficient; the small outer } \\
\text { diameter allows it to be } \\
\text { passed through pediatric } \\
\text { bronchoscopes }\end{array}$ & $\begin{array}{l}\text { Figure } 14 \\
(46)\end{array}$ \\
\hline Fishnet basket & Steris ${ }^{T M}$ & Single use & 2.8 & 230 & Not applicable & $\begin{array}{c}\text { Not } \\
\text { applicable }\end{array}$ & $\begin{array}{l}\text { Net size: } 3 \times 6 \mathrm{~cm} \text {, Sheath } \\
\text { diameter } 2.5 \mathrm{~mm} \text {. Assists in } \\
\text { retrieval of smaller foreign } \\
\text { bodies }\end{array}$ & $\begin{array}{l}\text { Figure } 15 \\
(47)\end{array}$ \\
\hline
\end{tabular}

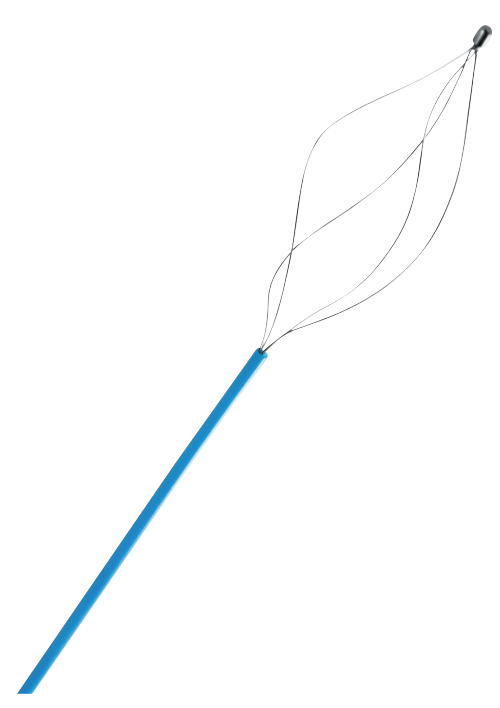

Figure 12 Mini grasping basket.

as compared to grasping forceps and by tightening around a FB like a noose provide sufficient grasping force to disengage it from the surrounding tissue (51). They are more useful for flat or elongated objects such as dental prosthesis, and are less likely to slip off compared to rounded bodies. Additionally, they are also suitable for pliable objects as a firm grip can be obtained (51-54).
Figure 13 Grasping basket.

\section{Balloon catbeters}

Balloon catheters have been used for FB removal for several decades and are extremely useful. The utility of Fogarty balloon catheters for extraction of endobronchial foreign bodies was first emphasized by Ullyot and Norman in 1968 (55). A Fogarty balloon catheter can be used for FBs impacted in the distal airways (Figure 17). It is inserted through the working channel of the bronchoscope and 


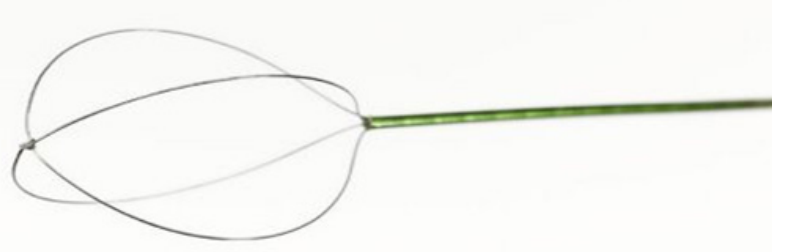

Figure 14 Zero tip airway retrieval basket

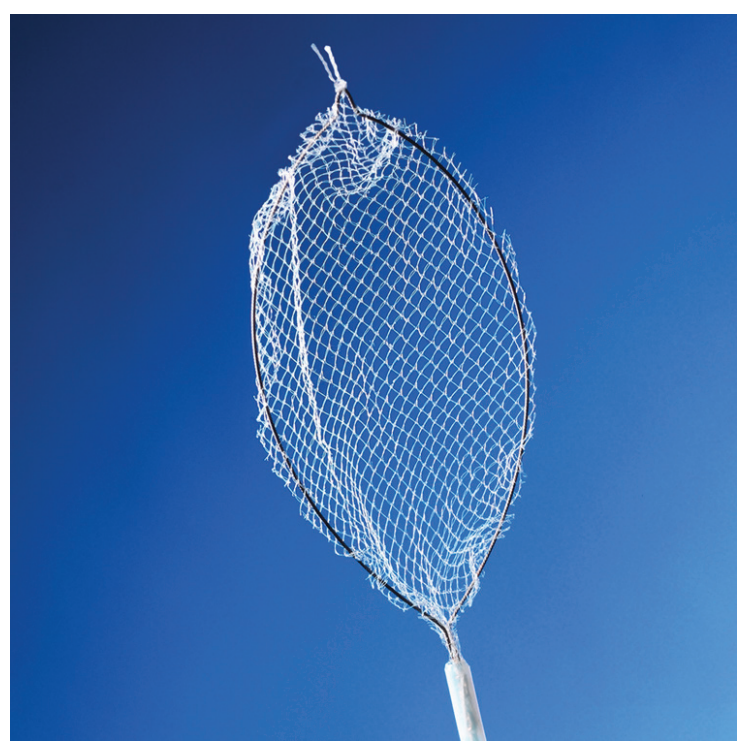

Figure 15 Fishnet basket. Courtesy of Steris Endoscopy. Unauthorized use not permitted.

maneuvered beyond the FB. The balloon at its distal end is then inflated with $1-3 \mathrm{~mL}$ of saline and pulled back to drag the FB into the central airway (Figure 18). This may require a few attempts especially when the $\mathrm{FB}$ is embedded in the airway wall. Once brought into the central airway, the FB is then retrieved with the use of an alligator forceps or wire basket. Fogarty catheters have also been used to extract FBs which have a central lumen where the catheter could be inserted through the central lumen (56-60). This however requires expertise in maneuvering the catheters. Complications with the use of Fogarty catheters are rare but have been reported in the literature. Incorrect technique
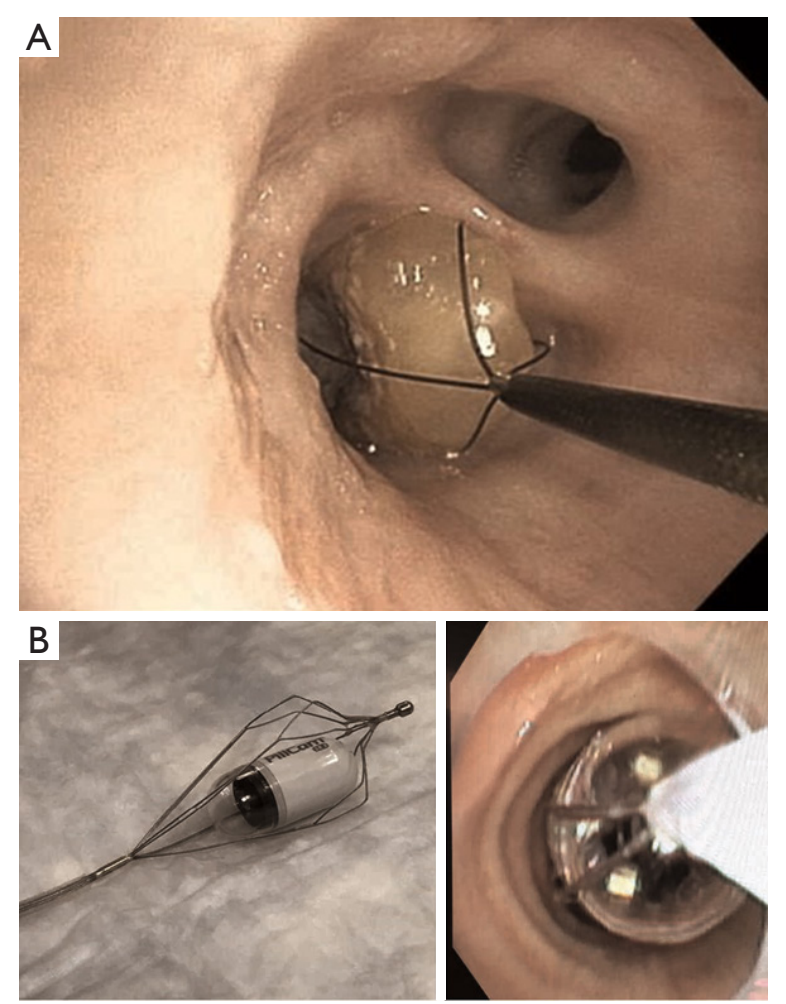

Figure 16 Foreign body extraction with two different type of baskets. (A) Zero tip (Boston Scientific ${ }^{\mathrm{TM}}$ ) basket encasing a corn kernel from right lower lobe; (B) Olympus ${ }^{\mathrm{TM}}$ "flower basket" used to extract a "Pillcam" from right lower lobe.

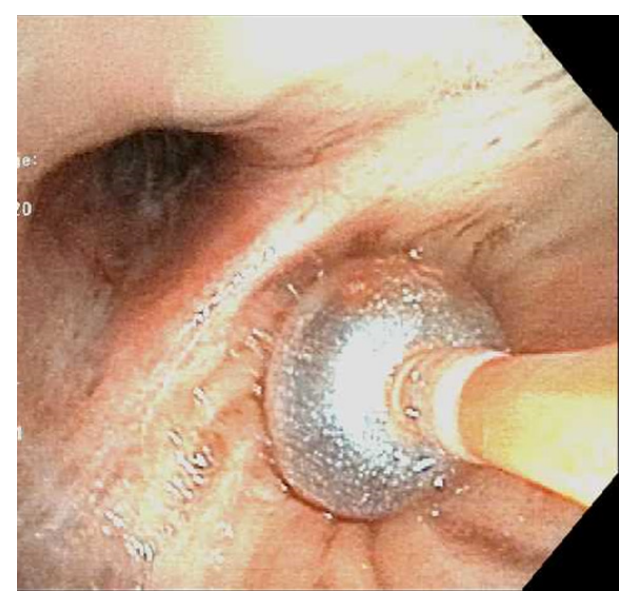

Figure 17 Fogarty balloon is used to tamponade bleeding airway mucosa after retrieval of foreign body.

or aggressive application of the balloon catheter can result in airway mucosal injury and bleeding. Pneumothorax or breakdown of the catheter tip, which itself becomes a FB that requires removal have been reported as well (61). 

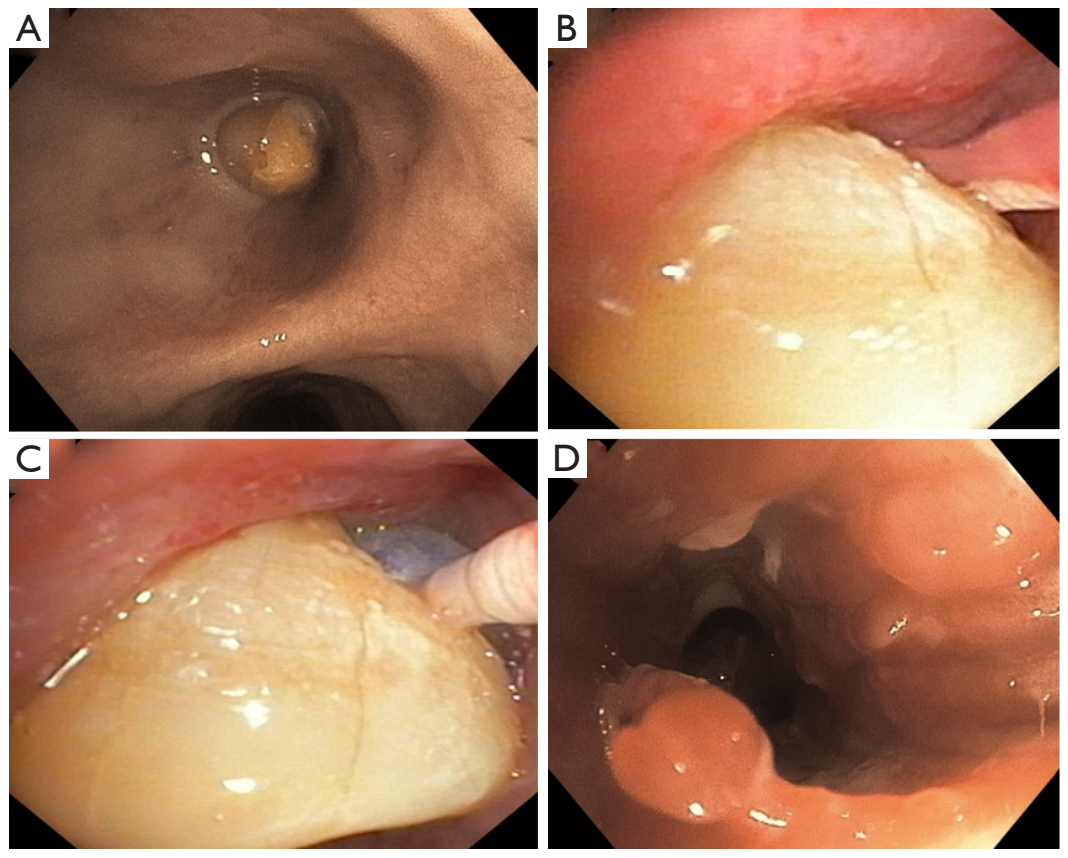

Figure 18 Fogarty balloon use to dislodge an impacted foreign body and bring it to the central airway is demonstrated. (A) Impacted foreign body; (B) Fogarty balloon passed beyond the foreign body; (C) Inflated Fogarty balloon being pulled back to dislodge the foreign body; (D) Granulation tissue at the site of foreign body impaction post-removal.

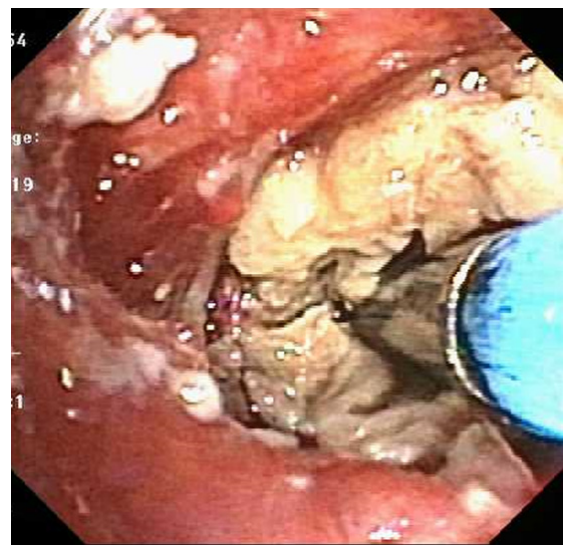

Figure 19 The cryoprobe is impaled into the foreign body (mucus cast) and freeze cycle is initiated. After, adequate cryoadhesion is visibly noticed, the foreign body is extracted by co-axial movement of the scope, the cryoprobe, and the adhered FB making sure that the cold probe doesn't catch the airway mucosa.

\section{Cryotherapy}

Cryotherapy is a diagnostic and therapeutic technique used during bronchoscopy. The technique was first used for devitalization of an endobronchial tumor by Gage in 1968 (62). Since its advent, cryoprobe has undergone various modifications and is now widely used in different clinical settings via a flexible bronchoscope. It is now being increasingly used for retrieval of foreign bodies using cryoadhesion principle (Figure 19). Foreign bodies that contain high water content for freezing and adhering to the cryoprobe, and that are difficult to remove with grasping forceps are ideally suited for removal by cryoprobe such as meat, pills, peanuts, teeth and bones. Cryoprobe is also very useful in removal of clots and mucus plugs, though they are not FBs in strict sense.

There are three main parts of a cryoprobe-based system: a cryogen, the liquefied gas under high pressure used to create the freezing temperatures, the Cryoconsole to regulate release of cryogen, and cryoprobe to deliver the cryogen. The most commonly used cryogen gas is Nitrous oxide as it can achieve temperatures lower than $-40{ }^{\circ} \mathrm{C}$. Carbon dioxide is used as an alternate and is considered to be environmentally safer and is economical. The cryoprobe is inserted through the working channel of the bronchoscope and is directed towards the FB. On contact with the FB, the cryogen is released and this rapidly freezes the $\mathrm{FB}$, which then adheres to the cryoprobe. Instilling few drops of saline may facilitate adhesion in case 
of desiccated objects. Saline can also be used to capture multiple small pieces simultaneously in one crystal. Unlike other applications like cryobiopsy where cryogenic effect is activated for a pre-determined time cycle, for FB removal the duration of activation is guided by video input. The operator has to freeze enough volume for a good grasp; however, caution is to be observed so that the adjoining mucosa does not form a part of the crystal. If it does, then the cryoprobe has to be thawed in situ and reattempt made by activating the cryogen for reduced time duration. The probe along with the FB is then pulled out of the airway. Cryogen may have to be kept activated during withdrawal to prevent falling off of the $\mathrm{FB}$, while maintaining coaxiality and avoiding contact with surrounding structures on the way out. This technique can be used with both flexible and rigid bronchoscopy.

Along with FB retrieval, cryotherapy also aids in the removal of devitalized granulation tissue that often accompanies impacted FB. The granulation tissue is sensitive to cryotherapy while tracheal and bronchial cartilaginous tissue are resistant to it. This principle helps in the lysis of residual granulation tissue at the site of $\mathrm{FB}$ obstruction $(63,64)$. Cryotherapy is a safe procedure with minimal complications, especially in context of $\mathrm{FB}$ removal, however, hemoptysis, bronchospasm, tracheoesophageal fistula and pneumothorax have been reported in the literature (65).

\section{Removal technique and post retrieval care}

In general, removal of a FB by flexible bronchoscopy is performed under conscious sedation and does not require deep sedation. However, general anesthesia is preferred when the $\mathrm{FB}$ aspiration is of longer duration, or suspected to be impacted or associated with post-obstructive infection. Also, rigid bronchoscopy requires patient to be deeply sedated and at times, with neuromuscular blockade. In situations where partial obstruction of trachea is suspected due to large FB, care should be exercised to maintain spontaneous ventilation to reduce the risk of converting obstruction from partial to complete (66). In critically ill patients who are in respiratory distress, a rigid bronchoscope with largest suitable barrel is preferred over a flexible bronchoscope as the former provides adequate room for ventilation and wider gauge for suction. If insertion of rigid bronchoscope is not feasible, it is essential to perform endotracheal intubation with large size tube to ensure adequate ventilation prior to the $\mathrm{FB}$ removal. The FB can then be removed by passing the bronchoscope through the ETT. Large FBs are often removed en bloc along with the ETT.

The formation of granulation tissue around the aspirated FB is common. This may make the removal more difficult and increase risk of bleeding. It may be necessary to perform ablation of granulation tissue prior to maneuvering the $\mathrm{FB}$ or dislodging it. Rarely, a staged procedure - destruction of granulation tissue followed by a repeat bronchoscopy to remove the embedded FB may be necessary. Once the FB is grasped, the surrounding tissue should be visualized carefully and the FB should be maneuvered out from its embedded state such that the bronchoscopist has full visualization of the FB within the lumen.

Care should be also be exercised to prevent pushing the FB distally into the airway. It is common to use a Fogarty balloon to mobilize the FB from the distal to the proximal airway. Once the FB is in the central airway, it is securely held with a grasping instrument and removed from the airway along with the bronchoscope. It is important to keep the bronchoscope, grasping tool, and the accompanying FB co-axial to the airway lumen. This will ensure minimal drag of the FB with the airway wall and decrease risk of dropping it back in the airway. Oral route is always recommended to a nasal route for introducing flexible bronchoscope to avoid negotiating the nasal passages, even with smaller foreign bodies. Once the FB is retrieved, it is important for the bronchoscopist to perform a thorough survey of the airway to evaluate for any residual $\mathrm{FB}$, and assess for mucosal injury and resultant bleeding that may require additional interventions such as cautery or argon plasma coagulation.

\section{Special circumstances}

\section{Application of LASER in the retrieval of foreign bodies}

Large objects that cannot be grasped with a forcep or a basket can be removed with a cryoprobe if they are organic and moist. Others may need to be broken down into smaller parts before being extracted from the airway using LASER techniques (13,67-69). The neodymiumyttrium-aluminum-garnet (Nd:YAG) laser is the most commonly used type of laser during bronchoscopy. It provides deeper tissue penetration, better hemostasis and superior photocoagulation. It can be used with both flexible and rigid bronchoscopy. Boelcskei et al. have reported a case where an aspirated chicken bone was broken down by application of LASER beam and was then retrieved using biopsy forceps (70). Fruchter et al. have also reported two patients where LASER assisted bronchoscopic removal of 


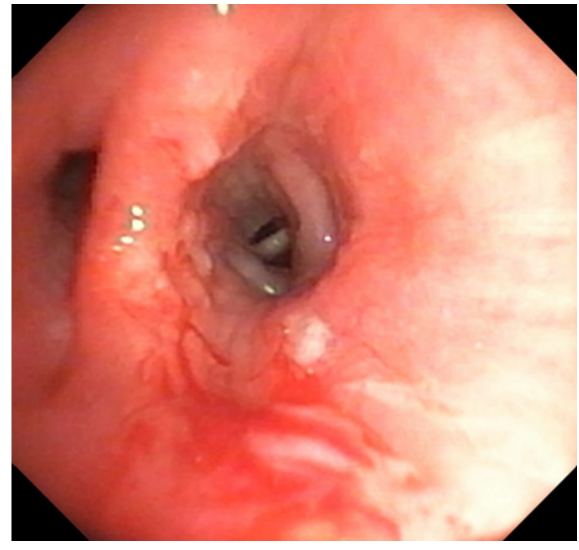

Figure 20 Airway mucosal injury resulting in bleeding during retrieval of an impacted foreign body. This was managed by using argon plasma coagulation.

thumbtacks was performed (71). Further, the use of Nd:YAG LASER may reduce the risk of mucosal bleeding due to its photocoagulation effect. Precautions should be taken to decrease risk of airway fire, including decreasing exhaled $\mathrm{FiO}_{2}$ to $<30 \%$, and using short pulses of energy delivery.

\section{Retrieval of sharp foreign bodies}

Removal of sharp objects can be specifically challenging and needs to be performed with utmost care. The strategy is to get hold of the sharp end of the object with the grasping instrument and gently separate it from the surrounding tissue. The object is then retrieved grasping the sharp end. This technique prevents the sharp end from causing trauma to the surrounding airway tissue. Extraction bags are useful in such situations as the sharp ends can be wrapped inside the bag. Additionally, the FB should be held close to the bronchoscope tip to have better control and grasp. At times, the distance between the FB and scope may need to be increased just before crossing the vocal cords to achieve best alignment through the glottic chink to avoid injury to the vocal cords. Co-axial motion ensures atraumatic retrieval of the $\mathrm{FB}$ and minimizes the risk of losing it back in the airway.

\section{FB aspiration through tracheostomy tube}

Aspiration of FB through the tracheostomy tube is a rare event but has been reported in the literature. Fraga $e t$ al. reported three such cases where FB aspiration occurred through the tracheostomy tube. In two of their patients, the FB could be successfully removed by bronchoscopy. However, a cervical tracheotomy had to be done in the third case as the object was too large to pass through the subglottis (72). It may be required to remove a larger FB and tracheostomy tube en bloc while a trained assistant is ready to insert a fresh tracheostomy tube through the established stoma.

\section{Iron pill aspiration syndrome}

Aspiration of iron pills, although rare, present unique challenges (73-77). A short contact of iron pill to the surrounding mucosa is known to cause local erythema and irritation. If the pill is not removed promptly, it results in ulceration of the bronchial mucosa, tissue necrosis and as a result of abnormal repair, symptomatic bronchial stenosis. Caterino et al. published a three patient case series of patients with iron pill inhalation. The authors were able to remove the iron pill with interventional bronchoscopy in two patients. The third patient required pulmonary bilobectomy after a failed bronchial stent placement (78). Chu et al. also described a case of iron pill aspiration causing obliterative bronchiolitis where multiple bronchoscopies, cryotherapy and balloon dilation were performed to relieve bronchial stenosis. However, these attempts were not completely successful and the patient remained symptomatic (79). Highindex of suspicion and prompt removal of aspirated iron pills may reduce risk of delayed complications.

\section{Complications}

\section{Bleeding}

Bleeding may occur due to the mucosal tissue injury during removal of the FB from the tethered granulation tissue (Figure 20). It is usually minor and is easily managed using electrocautery or argon plasma coagulation. A preprocedure CT angiogram may help evaluate risk of lifethreatening bleeding during removal of the long-standing impacted FB. Bronchial artery embolization may be performed if anomalous blood supply is noted to the area. Multi-disciplinary approach to FB removal including an early thoracic surgery consultation is encouraged in these circumstances.

\section{Asphyxiation}

Asphyxiation during FB removal is a life-threatening 
complication. The swelling of aspirated objects by absorption of moisture is reported in the literature (13). This sometimes, changes a partial obstruction into a complete obstruction (80) and therefore, predisposes to asphyxiation.

When an attempt is made to remove a large FB from the mainstem bronchus, it sometimes drops in the trachea and may change its orientation causing central airway obstruction and resultant asphyxiation. If such an event occurs, the proceduralist must be prepared to push the FB back into the mainstem bronchi to avoid tracheal obstruction. Repeat attempts at FB removal are performed once adequate ventilation is established.

\section{Trauma}

Trauma to vocal cords or rarely laceration or perforation of airway wall may occur with removal of impacted foreign bodies. In case of such a complication, it is important to ensure adequate ventilation and control any associated hemorrhage.

\section{Training and education}

Safe and successful extraction of airway FB using bronchoscopy requires specialized training and expertise in advanced bronchoscopy. In United States, training in bronchoscopic airway FB extraction falls within the scope of Interventional Pulmonology (IP). IP is a relatively young field and it is only recently, that accreditation standards for list of procedures that training programs are mandated to offer during IP fellowship were published (81). Even so, specialized training in the removal of airway FBs may be limited during these fellowships due to a variety of reasons including: the overall low incidence of FB aspiration and the steep learning curve of gaining expertise in these advanced procedures. In a systematic review, Sehgal et al. reported that only 1 in 400 bronchoscopies were performed for FB extraction over a period of more than three decades (13). In such a scenario, the use of simulation techniques is very helpful for training and skill development (82) (Video 1). Simulation based procedural training has been demonstrated to improve the learning curve and selfreported confidence among trainees (83). With the expected growth of IP fellowship programs in the US and worldwide, the utilization of simulation tools in the training of IP physicians and proceduralists is imperative.

\section{Summary}

FB aspiration is an uncommon event among adults; but is associated with significant morbidity and rarely, even mortality. Early identification and removal of FB is important to prevent associated complications. Flexible bronchoscopy remains mainstay for FB removal among adults but rigid bronchoscopy may be required in select circumstances. The use of interventional bronchoscopic techniques for FB removal requires specialized training and experience that may not be available at all centers. Each case of $\mathrm{FB}$ aspiration poses a different challenge and ingenuity is often required for successful removal of $\mathrm{FB}$ from the tracheobronchial tree. A team-based approach on part of interventional pulmonology or intensivist, anesthesiology and thoracic surgery is likely to improve the success of these procedures for optimal outcomes.

\section{Acknowledgments}

Funding: None.

\section{Footnote}

Provenance and Peer Review: This article was commissioned by the editorial office, Fournal of Thoracic Disease for the series "Interventional Pulmonology in the Intensive Care Unit Environment". The article has undergone external peer review.

Conflicts of Interest: All authors have completed the ICMJE uniform disclosure form (available at: http://dx.doi. org/10.21037/jtd.2020.03.94). The series "Interventional Pulmonology in the Intensive Care Unit Environment" was commissioned by the editorial office without any funding or sponsorship. Ashutosh Sachdeva served as the unpaid Guest Editor of the series. The authors have no other conflicts of interest to declare.

Ethical Statement: The authors are accountable for all aspects of the work in ensuring that questions related to the accuracy or integrity of any part of the work are appropriately investigated and resolved.

Open Access Statement: This is an Open Access article distributed in accordance with the Creative Commons Attribution-NonCommercial-NoDerivs 4.0 International License (CC BY-NC-ND 4.0), which permits the non- 
commercial replication and distribution of the article with the strict proviso that no changes or edits are made and the original work is properly cited (including links to both the formal publication through the relevant DOI and the license). See: https://creativecommons.org/licenses/by-ncnd/4.0/.

\section{References}

1. Salih AM, Alfaki M, Alam-Elhuda DM. Airway foreign bodies: A critical review for a common pediatric emergency. World J Emerg Med 2016;7:5-12.

2. Zöllner F. Gustav Killian, father of bronchoscopy. Arch Otolaryngol 1965;82:656-9.

3. Rafanan AL, Mehta AC. Adult airway foreign body removal. What's new? Clin Chest Med 2001;22:319-30.

4. Baharloo F, Veyckemans F, Francis C, et al. Tracheobronchial foreign bodies: presentation and management in children and adults. Chest 1999;115:1357-62.

5. Blanco Ramos M, Botana-Rial M, Garcia-Fontan E, et al. Update in the extraction of airway foreign bodies in adults. J Thorac Dis 2016;8:3452-6.

6. Lin L, Lv L, Wang Y, et al. The clinical features of foreign body aspiration into the lower airway in geriatric patients. Clin Interv Aging 2014;9:1613-8.

7. Debeljak A, Sorli J, Music E, et al. Bronchoscopic removal of foreign bodies in adults: experience with 62 patients from 1974-1998. Eur Respir J 1999;14:792-5.

8. Mise K, Jurcev Savicevic A, Pavlov N, et al. Removal of tracheobronchial foreign bodies in adults using flexible bronchoscopy: experience 1995-2006. Surg Endosc 2009;23:1360-4.

9. Limper AH, Prakash UBS. Tracheobronchial Foreign Bodies in Adults. Ann Intern Med 1990;112:604-9.

10. Boyd M, Watkins F, Singh S, et al. Prevalence of flexible bronchoscopic removal of foreign bodies in the advanced elderly. Age Ageing 2009;38:396-400.

11. Chen CH, Lai CL, Tsai TT, et al. Foreign body aspiration into the lower airway in Chinese adults. Chest 1997;112:129-33.

12. Lan RS. Non-asphyxiating tracheobronchial foreign bodies in adults. Eur Respir J 1994;7:510-4.

13. Sehgal IS, Dhooria S, Ram B, et al. Foreign Body Inhalation in the Adult Population: Experience of 25,998 Bronchoscopies and Systematic Review of the Literature. Respir Care 2015;60:1438-48.

14. Palasamudram Shekar S, Bajarano P, Hadeh A, et al. Case of Missing Plastic: Foreign Body Bronchiectasis. Cureus 2018;10:e2974.

15. Pritt B, Harmon M, Schwartz M, et al. A tale of three aspirations: foreign bodies in the airway. J Clin Pathol 2003;56:791-4.

16. Mercado JA, Rodriguez W. Occult aspiration of a chicken wishbone as a cause of hemoptysis. P R Health Sci J 1999;18:71-3.

17. al-Majed SA, Ashour M, al-Mobeireek AF, et al. Overlooked inhaled foreign bodies: late sequelae and the likelihood of recovery. Respir Med 1997;91:293-6.

18. Maayan C, Avital A, Elpeleg ON, et al. Complications following oat head aspiration. Pediatr Pulmonol 1993;15:52-4.

19. Goussard P, Gie R, Andronikou S, et al. Organic foreign body causing lung collapse and bronchopleural fistula with empyema. BMJ Case Rep 2014;2014:bcr2014204633.

20. Wong SC, Tariq SM. Cardiac arrest following foreignbody aspiration. Respir Care 2011;56:527-9.

21. Kashif M, Talib Hashmi HR, Khaja M. Early Recognition of Foreign Body Aspiration as the Cause of Cardiac Arrest. Case Rep Crit Care 2016;2016:1329234.

22. Shlamovitz GZ, Halpern P. Delayed obstruction of endotracheal tubes by aspirated foreign bodies: report of two cases. Ann Emerg Med 2004;43:630-3.

23. Alwassia AA, Jose A, Raddaoui L, et al. Endotracheal Tube Obstruction Due to Aspirated Foreign Bodies: An Overview of Etiology, Diagnosis, and Management. Clin Pulm Med 2018;25:20-2.

24. Ramos MB, Fernandez-Villar A, Rivo JE, et al. Extraction of airway foreign bodies in adults: experience from 19872008. Interact Cardiovasc Thorac Surg 2009;9:402-5.

25. Limper AH, Prakash UB. Tracheobronchial foreign bodies in adults. Ann Intern Med 1990;112:604-9.

26. Jain A, Naithani $M$, Chaudhary Z, et al. Rare iatrogenic airway foreign body: The rivet from the fulcrum of the McCoy laryngoscope blade. Indian J Anaesth 2012;56:301-2.

27. Hard C, Nargozian CD. Iatrogenic Airway Foreign Body. Anesthesiology 1984;61:786.

28. Ng J, Kim S, Chang B, et al. Clinical features and treatment outcomes of airway foreign body aspiration in adults. J Thorac Dis 2019;11:1056-64.

29. Tseng HJ, Hanna TN, Shuaib W, et al. Imaging Foreign Bodies: Ingested, Aspirated, and Inserted. Ann Emerg Med 2015;66:570-82.e5.

30. Goussard P, Mfingwana L, Morrison J. Removal of distal airway foreign body with the help of fluoroscopy in a child. 
Pediatr Pulmonol 2020;55:E5-7.

31. Yüksel M, Ozyurtkan MO, Lacin T, et al. The role of fluoroscopy in the removal of tracheobronchial pin aspiration. Int J Clin Pract 2006;60:1451-3.

32. Gill SS, Pease RA, Ashwin CJ, et al. Respiratory-aspirated 35-mm hairpin successfully retrieved with a Teflon(R) snare system under fluoroscopic guidance via a split endotracheal tube: a useful technique in cases of failed extraction by bronchoscopy and avoiding the need for a thoracotomy. Br J Radiol 2012;85:e756-9.

33. Ikeda S, Yanai N, Ishikawa S. Flexible bronchofiberscope. Keio J Med 1968;17:1-16.

34. Swanson KL. Airway foreign bodies: what's new? Semin Respir Crit Care Med 2004;25:405-11.

35. Boufersaoui A, Smati L, Benhalla KN, et al. Foreign body aspiration in children: experience from 2624 patients. Int J Pediatr Otorhinolaryngol 2013;77:1683-8.

36. Huang PM, Kao MW. Endobronchial foreign body removed by flexible bronchoscopy using the Trendelenburg position. Thorac Cardiovasc Surg 2012;60:545-7.

37. Zhijun C, Fugao Z, Niankai Z, et al. Therapeutic experience from 1428 patients with pediatric tracheobronchial foreign body. J Pediatr Surg 2008;43:718-21.

38. Hsu AA. Endoscopic intervention of lower airway foreign matter in adults-a different perspective. J Thorac Dis 2015;7:1870-7.

39. Olympus. V-Shape Grasping Forceps. Retrieved Febuary 5th, 2020. Available online: https://medical. olympusamerica.com/products/forceps/v-shape-fg-25c-1

40. Olympus. Rat tooth Grasping Forceps. Retrieved Febuary 5th, 2020. Available online: https://medical. olympusamerica.com/products/forceps/rat-tooth-fg$26 \mathrm{c}-1$.

41. Olympus. Shark Tooth Grasping Forceps. Retrieved Febuary 5th, 2020. Available online: https://medical. olympusamerica.com/products/forceps/shark-tooth-fg$32 \mathrm{c}-1$

42. Olympus. Rubber Tip Grasping Forceps. Retrieved Febuary 5th 2020. Available online: https://medical.olympusamerica. com/products/forceps/rubber-tip-fg-20p-1

43. Olympus. Single-Use Mini Three-Prong Grasping Forceps. Retrieved Febuary 5th, 2020. Available online: http://212.18.82.39/en/index.php? category=7984

44. Olympus. Single-Use Mini Grasping Baskets. Retrieved Febuary 5th, 2020. Available online: http://212.18.82.39/ en/index.php? category $=7589$

45. Olympus. Reusable Grasping Baskets. Retrieved Febuary 5th, 2020. Available online: http://212.18.82.39/en/index. php?category $=7584$

46. Scientific B. Zero Tip ${ }^{\mathrm{TM}}$ Nitinol Stone Retrieval Basket. Retrieved Febuary 5th, 2020. Available online: https:// www.bostonscientific.com/content/gwc/en-US/products/ retrieval-devices/zero-tip.html

47. Steris. Roth Net Standard Retrievers. Retrieved Febuary 5th, 2020. Available online: https://www.steris.com/ healthcare/products/endoscopy-devices/roth-net-retrievaldevices/roth-net-foreign-body-retrievers/roth-netstandard-retrievers

48. Dormia E. Dormia basket: Standard technique, observations, and general concepts. Urology 1982;20:437.

49. Freiman MA, McMurray JS. Unique presentation of a bronchial foreign body in an asymptomatic child. Ann Otol Rhinol Laryngol 2001;110:495-7.

50. Varshney R, Zawawi F, Shapiro A, et al. Use of an endoscopic urology basket to remove bronchial foreign body in the pediatric population. Int J Pediatr Otorhinolaryngol 2014;78:687-9.

51. Ichimura H, Maeda M, Kikuchi S, et al. Endobronchial dental prosthesis retrieval by a snare technique using a flexible bronchoscope and fluoroscopy: Two case reports and technical tips. Respir Med Case Rep 2016;19:187-9.

52. Jamshed N, Madan K, Ekka M, et al. Successful flexible bronchoscopic management of a large-sized aspirated partial denture. BMJ Case Rep 2014;2014:bcr2013202371.

53. Tu CY, Chen HJ, Chen W, et al. A feasible approach for extraction of dental prostheses from the airway by flexible bronchoscopy in concert with wire loop snares. Laryngoscope 2007;117:1280-2.

54. Umapathy N, Panesar J, Whitehead BF, et al. Removal of a foreign body from the bronchial tree--a new method. J Laryngol Otol 1999;113:851-3.

55. Ullyot DG, Norman JC. The Fogarty Catheter: An Aid to Bronchoscopic Removal of Foreign Bodies. The Annals of Thoracic Surgery 1968;6:185-6.

56. Wankhede RG, Maitra G, Pal S, et al. Successful Removal of Foreign Body Bronchus Using C-arm-guided Insertion of Fogarty Catheter through Plastic Bead. Indian J Crit Care Med 2017;21:96-8.

57. Bawa M, Kalawant A, Vinod MS, et al. Unsuccessful Retrieval of Impacted Foreign Body Bronchus: Think about Fogarty Catheter. Indian J Pediatr 2016;83:744-5.

58. Mackle T, Russell J. The combined use of a Fogarty balloon with extraction forceps for the controlled retrieval of an endobronchial foreign body. Int J Pediatr Otorhinolaryngol 2001;60:163-5.

59. Landy C, Massoure PL, Gauthier J, et al. Use of a Fogarty 
catheter after tracheobronchial inhalation of a bead. Trop Doct 2012;42:219-20.

60. Elsharkawy H, Abd-Elsayed AA, Karroum R. Management challenges in the passing-through technique using a fogarty catheter to remove an endobronchial foreign body from an infant. Ochsner J 2015;15:110-3.

61. Treen DC, Falterman KW, Arensman RM.

Complications of the fogarty catheter technique for removal of endobronchial foreign bodies. J Pediatr Surg 1989;24:613-5.

62. Gage AA. Cryotherapy for cancer. Cryosurgery. Springfield: Charles C. Thomas, 1968;376-87.

63. DiBardino DM, Lanfranco AR, Haas AR. Bronchoscopic Cryotherapy. Clinical Applications of the Cryoprobe, Cryospray, and Cryoadhesion. Ann Am Thorac Soc 2016;13:1405-15.

64. Maiwand MO, Zehr KJ, Dyke CM, et al. The role of cryotherapy for airway complications after lung and heart-lung transplantation. Eur J Cardiothorac Surg 1997;12:549-54.

65. Thommi G, McLeay M. Cryobronchoscopy in the management of foreign body in the tracheobronchial tree. Chest 1998;114:303S.</jrn>

66. Fidkowski CW, Zheng H, Firth PG. The anesthetic considerations of tracheobronchial foreign bodies in children: a literature review of 12,979 cases. Anesth Analg 2010;111:1016-25.

67. Dong YC, Zhou GW, Bai C, et al. Removal of tracheobronchial foreign bodies in adults using a flexible bronchoscope: experience with 200 cases in China. Intern Med 2012;51:2515-9.

68. Boelcskei PL, Wagner M, Lessnau KK. Laser-assisted removal of a foreign body in the bronchial system of an infant. Lasers Surg Med 1995;17:375-7.

69. Mahajan AK, Khandhar SJ. Successful Bronchoscopic Removal of a Chicken Bone Lodged in the Airway for 4 Years. Am J Respir Crit Care Med 2016;194:e8-e9.

70. Boelcskei PL, Wagner M, Lessnau K-DKL. Laser-assisted removal of a foreign body in the bronchial system of an infant. Lasers Surg Med 1995;17:375-7.

71. Fruchter O, Fox BD, Raviv Y, et al. Laser-Assisted Removal of Aspirated Thumbtacks by Flexible

Cite this article as: Bajaj D, Sachdeva A, Deepak D. Foreign body aspiration. J Thorac Dis 2021;13(8):5159-5175. doi: $10.21037 /$ jtd.2020.03.94
Bronchoscopy. Diagn Ther Endosc 2010;2010:598760.

72. Fraga JC, Pires AF, Komlos M, et al. Bronchoscopic removal of foreign body from airway through tracheotomy or tracheostomy. J Pediatr (Rio J) 2003;79:369-72.

73. Kim ST, Kaisar OM, Clarke BE, et al. 'Iron lung': distinctive bronchoscopic features of acute iron tablet aspiration. Respirology 2003;8:541-3.

74. Lee P, Culver DA, Farver C, et al. Syndrome of iron pill aspiration. Chest 2002;121:1355-7.

75. Jimenez Rodriguez BM, de Jesús SC, Merinas López $\mathrm{CM}$, et al. Bronchial Stenosis After Iron Pill Aspiration. Journal of Bronchology \& Interventional Pulmonology 2013;20:96-7.

76. Lamaze R, Trechot P, Martinet Y. Bronchial necrosis and granuloma induced by the aspiration of a tablet of ferrous sulphate. Eur Respir J 1994;7:1710-1.

77. Godden DJ, Kerr KM, Watt SJ, et al. Iron lung: bronchoscopic and pathological consequences of aspiration of ferrous sulphate. Thorax 1991;46:142-3.

78. Caterino U, Battistoni P, Batzella S, et al. Syndrome of iron pill inhalation in four patients with accidental tablet aspiration: Severe airway complications are described. Respiratory medicine case reports 2015;15:33-5.

79. Chu A, Krishna A, Paul MP, et al. Obliterating Bronchiolitis: Result of Iron Pill Aspiration. Cureus 2018;10:e2571.

80. Overdahl MC, Wewers MD. Acute occlusion of a mainstem bronchus by a rapidly expanding foreign body. Chest 1994;105:1600-2.

81. Mullon JJ, Burkart KM, Silvestri G, et al. Interventional Pulmonology Fellowship Accreditation Standards: Executive Summary of the Multisociety Interventional Pulmonology Fellowship Accreditation Committee. Chest 2017;151:1114-21.

82. Desai NR, Parikh MS, Lee HJ. Interventional Pulmonology: The Role of Simulation Training and Competency-Based Evaluation. Semin Respir Crit Care Med 2018;39:747-54.

83. Hinchcliff M, Kao M, Johnson K. The importance of technical skills assessment during an airway foreign body removal course. Int J Pediatr Otorhinolaryngol 2019;117:1-5. 